\title{
Risk factors and analysis of long-term headache in sporadic vestibular schwannoma: a multicenter cross-sectional study
}

\author{
Matthew L. Carlson, MD, ${ }^{1,2}$ Øystein Vesterli Tveiten, MD, ${ }^{5}$ Colin L. Driscoll, MD, ${ }^{1,2}$ \\ Christopher J. Boes, MD, ${ }^{3}$ Molly J. Sullan, BA, ${ }^{1}$ Frederik K. Goplen, MD, PhD, ${ }^{4}$ \\ Morten Lund-Johansen, MD, PhD, ${ }^{5,6}$ and Michael J. Link, MD ${ }^{1,2}$
}

Departments of ${ }^{1}$ Otolaryngology-Head and Neck Surgery, ${ }^{2}$ Neurologic Surgery, and ${ }^{3}$ Neurology, Mayo Clinic School of Medicine, Rochester, Minnesota; Departments of ${ }^{4}$ Otolaryngology and ${ }^{5}$ Neurosurgery, Haukeland University Hospital; and ${ }^{6}$ Institute of Surgical Sciences, University of Bergen, Norway

OBJECT The primary goals of this study were: 1) to examine the influence of disease and treatment on headache in patients with sporadic vestibular schwannoma (VS); and 2) to identify clinical predictors of long-term headache disability.

\begin{abstract}
METHODS This was a cross-sectional observational study with international multicenter enrollment. Patients included those with primary sporadic $<3-\mathrm{cm}$ VS and a separate group of general population control subjects without tumors. Interventions included a postal survey incorporating the Headache Disability Inventory (HDI), the Hospital Anxiety and Depression Scale, and a VS symptom questionnaire. The main outcome measures were univariate and multivariable associations with $\mathrm{HDI}$ total score.

RESULTS The overall survey response rate was $79 \%$. Data from 538 patients with VS were analyzed. The mean age at time of survey was 64 years, $56 \%$ of patients were female, and the average duration between treatment and survey was 7.7 years. Twenty-seven percent of patients received microsurgery, $46 \%$ stereotactic radiosurgery, and $28 \%$ observation. Patients with VS who were managed with observation were more than twice as likely to have severe headache disability compared with 103 control subjects without VS. When accounting for baseline differences, there was no statistically significant difference in HDI outcome between treatment modalities at time of survey. Similarly, among the microsurgery cohort, the long-term risk of severe headache disability was not different between surgical approaches. Multivariable regression demonstrated that younger age, greater anxiety and depression, and a preexisting diagnosis of headache were the primary predictors of severe long-term headache disability, while tumor size and treatment modality had little influence.
\end{abstract}

CONCLUSIONS At a mean of almost 8 years following treatment, approximately half of patients with VS experience headaches of varying frequency and severity. Patient-driven factors including age, sex, mental health, and preexisting headache syndrome are the strongest predictors of long-term severe headache disability. Tumor size and treatment modality have less impact. These data may assist with patient counseling regarding long-term expectations following diagnosis and treatment.

http://thejns.org/doi/abs/10.3171/2014.12.JNS142109

KEY WORDS headache; pain; microsurgery; stereotactic radiosurgery; Gamma Knife radiosurgery; acoustic neuroma; vestibular schwannoma; cerebellopontine angle; oncology; cephalgia

$\mathrm{O}$ VER the last 100 years, the treatment of vestibular schwannoma (VS) has undergone tremendous evolution. ${ }^{32}$ With the increasing use of less invasive management methods including observation, stereotactic radiosurgery (SRS), or radiotherapy and subtotal or neartotal resection, incidences of disease-associated mortality, stroke, and permanent facial neuropathy have been substantially reduced. ${ }^{12,27,32,41}$ Given this, many investigators

ABBREVIATIONS CPA = cerebellopontine angle; HADS = Hospital Anxiety and Depression Scale; HDI = Henry Ford Hospital Headache Disability Inventory; HRQOL = health-related quality of life; ICHD-II = International Classification of Headache Disorders, Second Edition; IQR = interquartile range; PANQOL = Penn Acoustic Neuroma Quality of Life; SRS = stereotactic radiosurgery; VS = vestibular schwannoma.

SUBMITTED September 8, 2014. ACCEPTED December 4, 2014.

INCLUDE WHEN CITING Published online June 19, 2015; DOI: 10.3171/2014.12.JNS142109.

DISCLOSURE Dr. Driscoll is a consultant for Advanced Bionics Corp., Cochlear Corp., and MED-EL GmbH. 
have begun analyzing patient-reported outcome measures in an effort to further define disease-related morbidity and to examine the effects of treatment. ${ }^{11,27}$

Previous studies have demonstrated that among patients with sporadic VS, ongoing dizziness and headache are associated with the greatest health-related quality of life (HRQOL) reduction, whereas the contributions of unilateral hearing loss, tinnitus, and facial neuropathy are generally less by comparison. ${ }^{2-4,22,26}$ Despite the substantial physical and emotional burden associated with headache in patients with VS, this condition remains understudied. To our knowledge, no publications have specifically characterized headache in patients with VS receiving SRS or conservative observation. Additionally, there have been no studies in the surgical literature that have used validated headache disability inventories.

In a recent study, we evaluated long-term HRQOL outcomes between patients who were treated with microsurgery, SRS, and observation, using 3 generic measures and a recently validated disease-specific instrument, the Penn Acoustic Neuroma Quality of Life (PANQOL) scale. ${ }^{5} \mathrm{We}$ found that the greatest reduction of HRQOL resulted from the disease itself, while long-term differences between treatment modalities were generally small. Only 3 of the 7 PANQOL domains demonstrated a statistically significant difference during global comparison: facial function, balance, and pain, with the latter exhibiting the largest difference between treatment arms. Although the 26 -item PANQOL scale was found to be superior to other multipurpose HRQOL inventories at analyzing differences between treatment groups, it should be noted that the PANQOL scale uses only one question to determine pain outcome.

The current study sought to further characterize features of headache in a large multicenter cohort of patients with sporadic VS by using a validated headache disability inventory. First, a comparison of headache parameters was performed between a cohort of patients who were conservatively observed and a cohort of control patients without tumors to elucidate the contribution of disease alone on long-term headache. Second, a comparison of headache outcomes between patients who received observation, SRS, and microsurgery was performed to determine the influence of treatment modality on headache disability inventory scores. Last, pretreatment clinical variables were analyzed to determine high-risk features associated with long-term headache disability among all patients with VS.

\section{Methods \\ Inclusion/Exclusion Criteria and Data Acquisition}

Following institutional review board approval, all patients with VS who were evaluated between 1998 and 2008 at 2 independent tertiary medical centers were examined. All adult patients ( $\geq 18$ years old) with primary sporadic small- to medium-sized $(<3 \mathrm{~cm})$ VS were identified. Patients with neurofibromatosis Type 2, those who received treatment before 1998, patients who required more than one form of treatment (e.g., SRS after microsurgery), patients with tumors $>3 \mathrm{~cm}$, and patients under the age of 18 years were excluded. Clinical data regarding patient demographics, tumor size, presence of hydrocephalus, and treatment parameters were collected. Tumor size was classified according to the 1995 American Academy of Otolaryngology-Head and Neck Surgery guidelines. ${ }^{7}$

Eligible patients were surveyed with a postal questionnaire containing the Henry Ford Hospital Headache Disability Inventory (HDI), the Hospital Anxiety and Depression Scale (HADS), and a VS symptom questionnaire. ${ }^{18,48}$ Additionally, a population of adult nontumor controls was surveyed for comparison. The latter group was identified from a contact list purchased from a survey research firm (Marketing Systems Group). All US survey respondents were given monetary remuneration of 30 US dollars. All initial nonresponders received one additional follow-up letter or phone call regarding study participation.

\section{Description of Validated Patient-Reported Outcome Measures}

The HDI was developed and validated by Jacobson et al. in 1994 to assess the impact of headache on daily life and to determine response to treatment. ${ }^{18}$ The HDI is a 25 -item instrument that requires patients to select from 1 of 3 responses for each question, including "yes," "sometimes," and "no," with 4, 2, and 0 points assigned, respectively. Thus, the maximum (worst) score is 100 and the lowest (best) score is 0 .

The HADS was developed by Zigmond and Snaith in 1983 to assess the severity of anxiety, depression, and emotional distress in a medical outpatient setting and to determine progress with therapy. ${ }^{48}$ Several subsequent validation studies have confirmed good internal consistency and external validity ${ }^{16,31,40}$ Each of the 14 items includes 4 ordinal responses, each scored on a scale of $0-3$ points. Thus, the maximum (worst) possible total score is 42 and the lowest (best) possible score is 0 .

\section{Statistical Analysis}

Continuous features were summarized with means, medians, and interquartile ranges (IQRs); categorical features were summarized with frequency counts and percentages. Sample sizes for features with missing data are indicated in italics in parentheses in tables. Since nearly half of the patients studied had HDI total scores of 0 , the HDI was analyzed as $>0$ versus 0 to identify associations with patients with any degree of headache disability (Fig. 1). The HDI was also analyzed as $>14$ (i.e., the 75 th percentile of the distribution of HDI total scores) versus $\leq 14$ to identify associations with patients with severe headache disability. Associations with HDI total scores $>0$ and $>14$ were evaluated using logistic regression models and summarized with odds ratios and $95 \%$ confidence intervals. Multivariable models were developed using stepwise selection, with the $p$ value for a feature to enter or leave the model set to 0.05 . Comparisons between patients with VS who were observed and nontumor controls were evaluated using Wilcoxon rank-sum and chi-square tests. Comparisons of features among the SRS, observation, and microsurgery groups were evaluated using Kruskal-Wallis, chisquare, and Fisher exact tests. If the p value from a global test among the 3 groups was statistically significant, pairwise comparisons were evaluated using Wilcoxon ranksum, chi-square, and Fisher exact tests. Statistical analyses were performed using the SAS software package (SAS 


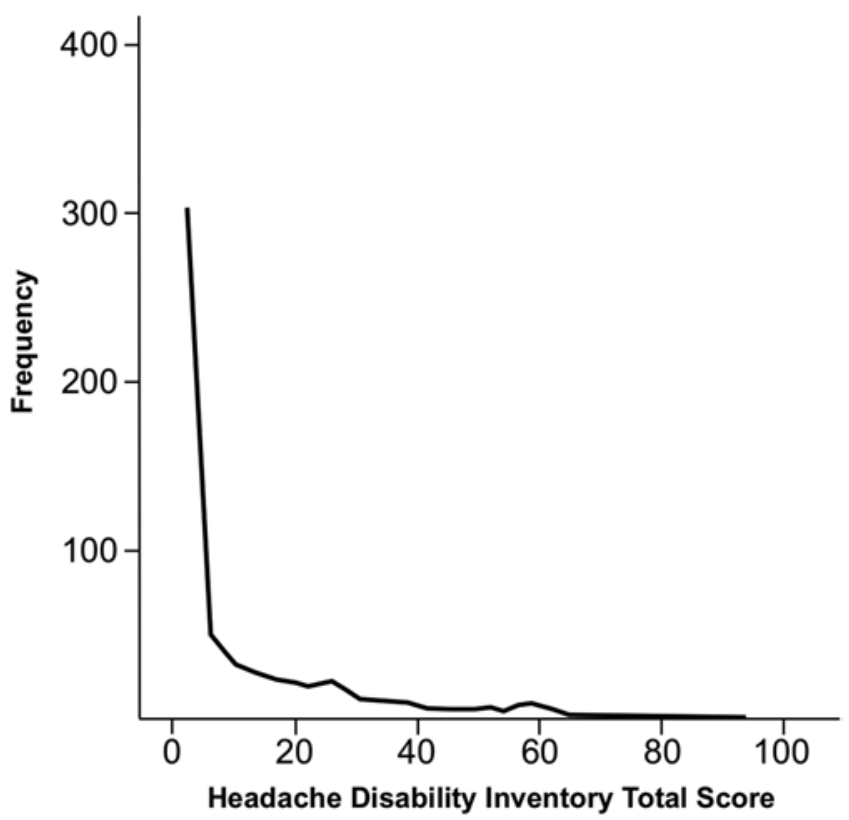

FIG. 1. Skewed distribution of HDI total score among 538 patients with sporadic VS.

Institute). All tests were 2 -sided and $\mathrm{p}$ values $<0.05$ were considered statistically significant.

\section{Results \\ Population Overview}

Data from 538 respondents were received and analyzed; 276 (51\%) were from the US and 262 (49\%) were from Norway. Seventy-nine percent of patients treated for VS who were successfully contacted returned a completed questionnaire set. Overall, the average age at time of survey was 64 years, $56 \%$ were women, and the mean time interval between treatment and survey was 7.7 years. Seventy-one percent of tumors demonstrated varying degrees of cerebellopontine angle (CPA) extension, whereas the remaining $29 \%$ were confined to the internal auditory canal. One hundred forty-three $(27 \%)$ patients received microsurgery, 247 (46\%) SRS, and 148 (28\%) conservative observation (Fig. 2). Additionally, data from 103 nontumor control subjects were analyzed. Sixty percent of patients with VS reported having headaches prior to treatment, and $19 \%$ had an established diagnosis of migraine. Overall, $15 \%$ thought that their headaches worsened following treatment, $14 \%$ believed that they had experienced improvement, and $70 \%$ did not perceive an appreciable change (Table 1).

\section{Impact of Disease on Headache}

A comparison of clinical features between 148 patients with observed VS and 103 nontumor controls was performed (Table 2). The control group was younger and there was a trend toward poorer HADS total scores compared with the observation cohort. Overall, there was no difference in frequency and severity of headache at baseline between groups; however, a history of migraines was more prevalent in the observation cohort.

At a mean of approximately 8 years following diagno-

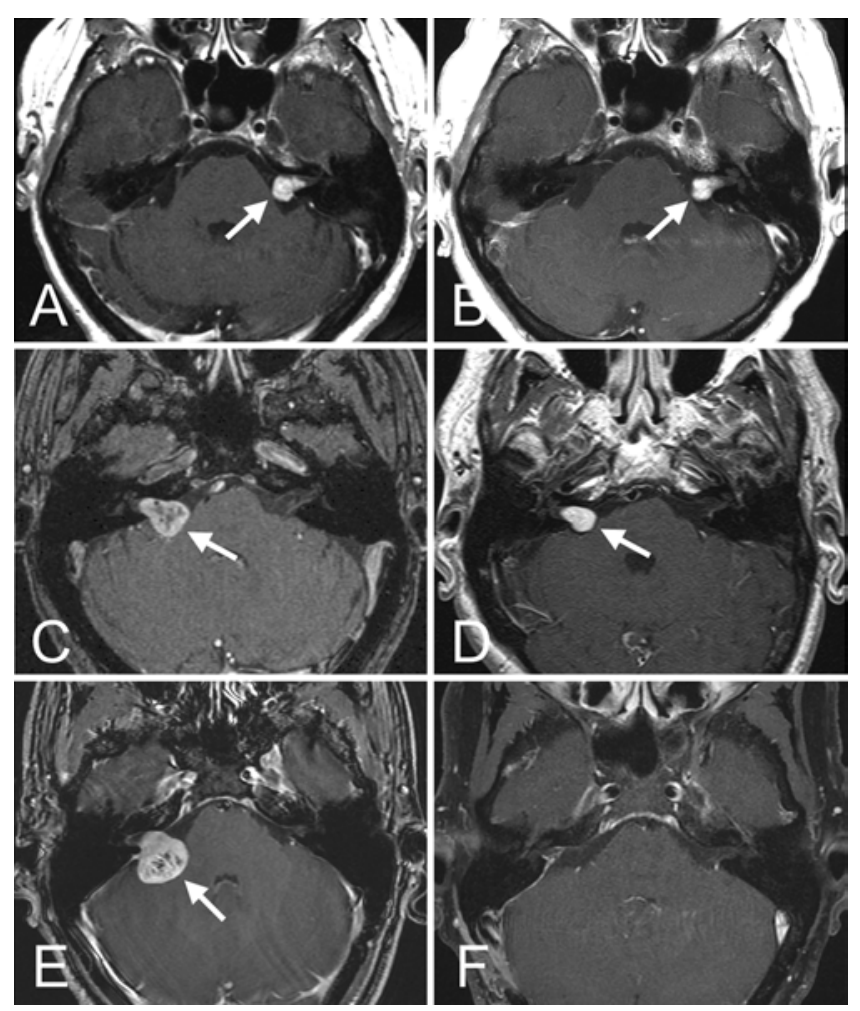

FIG. 2. Three management modalities for VS. A: A 67-year-old woman with serviceable hearing was referred after being diagnosed with a $1-\mathrm{cm}$ left-sided VS. B: Following 8 years of observation, the tumor remains unchanged, and the patient has only experienced minimal decline in hearing. C: A 62-year-old man presented for evaluation of a growing, $1.5-\mathrm{cm}$ right-sided VS. D: Five years following SRS, using a marginal dose of $12 \mathrm{~Gy}$, the tumor has decreased in size. E: A 33-year-old man with serviceable hearing was referred after being diagnosed with a 2.1$\mathrm{cm}$ right-sided VS. F: Four months following resection, the patient has maintained preoperative hearing levels and normal facial nerve function, and imaging confirms no evidence of residual tumor.

sis, the average HDI total score for the observation cohort was 8.5 (median 0; IQR 0-12; range 0-64), compared with 4.3 (median 0; IQR 0-4; range 0-46) for nontumor control subjects. Sixty-seven (45\%) of the 148 patients with VS who were observed had HDI total scores $>0$ compared with 30 (29\%) of the 103 nontumor controls. Univariately, the OR for the association of group (observation vs nontumor control) with HDI total scores $>0$ was $2.01(95 \%$ CI $1.18-3.43 ; \mathrm{p}=0.010)$. Thirty $(20 \%)$ of the patients who were observed had HDI total scores $>14$ compared with $11(11 \%)$ of the nontumor controls, resulting in a univariate OR for the association with HDI total scores $>14$ of 2.13 (95\% CI 1.01-4.47; $\mathrm{p}=0.047$ ). When controlling for the 2 variables that were most strongly associated with severe HDI in this subset (HADS and presence of headaches prior to treatment), the observation cohort was still statistically significantly more likely to have severe headache disability than the nontumor control group (multivariate OR 3.01; 95\% CI 1.20-7.56; $\mathrm{p}=0.019$ ).

\section{Impact of Treatment on Headache}

A comparison of clinical features among the SRS, observation, and microsurgery groups is shown in Table 3 . 
TABLE 1. Characteristics of 538 patients with VS

\begin{tabular}{|c|c|}
\hline Feature $^{*}$ & $\begin{array}{l}\text { Mean (median; } \\
\text { IQR) or No. (\%) }\end{array}$ \\
\hline \multicolumn{2}{|l|}{ Baseline } \\
\hline Age at survey (yrs) & $63.9(64 ; 55-72)$ \\
\hline Dx to survey (yrs) & $7.7(7.7 ; 5.6-9.3)$ \\
\hline \multicolumn{2}{|l|}{ Sex } \\
\hline Female & $303(56)$ \\
\hline Male & $235(44)$ \\
\hline \multicolumn{2}{|l|}{ Location } \\
\hline US & $276(51)$ \\
\hline Norway & $262(49)$ \\
\hline \multicolumn{2}{|l|}{ Pre-Tx } \\
\hline \multicolumn{2}{|l|}{ Tumor size $(n=533)$} \\
\hline Intracanalicular & $154(29)$ \\
\hline $0-9 \mathrm{~mm}$ CPA & $112(21)$ \\
\hline $10-19 \mathrm{~mm}$ CPA & $211(40)$ \\
\hline 20-30 mm CPA & $56(11)$ \\
\hline \multicolumn{2}{|l|}{ Hydrocephalus prior to $T x(n=459)$} \\
\hline No & $451(98)$ \\
\hline Yes & $8(2)$ \\
\hline \multicolumn{2}{|l|}{ Preexisting Dx of migraine } \\
\hline No & $435(81)$ \\
\hline Yes & $103(19)$ \\
\hline \multicolumn{2}{|l|}{ Presence of HAs prior to Tx $(n=537)$} \\
\hline No & $219(41)$ \\
\hline Yes, mild & $213(40)$ \\
\hline Yes, severe & $105(20)$ \\
\hline \multicolumn{2}{|l|}{ Tx modality } \\
\hline Observation & $148(28)$ \\
\hline SRS & $247(46)$ \\
\hline Microsurgery & $143(27)$ \\
\hline \multicolumn{2}{|l|}{ Post-Tx } \\
\hline HADS total score at time of survey $(n=537)$ & $6.2(5 ; 2-9)$ \\
\hline HDI total score at time of survey & $10(2 ; 0-14)$ \\
\hline \multicolumn{2}{|l|}{ Change in HAs following Tx $(n=530)$} \\
\hline Slightly better & $76(14)$ \\
\hline No change & $371(70)$ \\
\hline Somewhat worse & $55(10)$ \\
\hline Much worse & $28(5)$ \\
\hline \multicolumn{2}{|l|}{ Frequency of HAs over last several mos } \\
\hline$(n=535)$ & $308(58)$ \\
\hline Less than once per mo & $53(10)$ \\
\hline Once per mo & $91(17)$ \\
\hline Less than 4 per mo & $66(12)$ \\
\hline Less than daily & $17(3)$ \\
\hline Daily & \\
\hline \multicolumn{2}{|l|}{ Severity of ongoing HAs $(n=522)$} \\
\hline Mild & $334(64)$ \\
\hline Moderate & $152(29)$ \\
\hline Severe & $36(7)$ \\
\hline
\end{tabular}

Dx = diagnosis; $H A$ = headache; $T x$ = treatment.

* Sample sizes for features with missing data are indicated in parentheses.
Aside from tumor size, there were no baseline differences between treatment populations. At last follow-up, the microsurgery cohort had more frequent headaches; however, the perceived severity was not statistically significantly different between groups. Additionally, the percentage of respondents who reported worsening headaches after treatment was not different between groups. As outlined below, when accounting for baseline differences between groups, HDI total scores were not statistically significantly different among management modalities.

Of the 318 patients who reported having headaches prior to treatment, 109 (34\%) had severe headache disability (HDI > 14) at time of survey. Within this group, 48 (44\%) were treated with SRS, $25(23 \%)$ with observation, and 36 (33\%) with microsurgery. Univariately, among patients with preexisting headache, the risk for severe long-term headache disability was greatest for the microsurgery arm (OR 2.21; 95\% CI 1.18-4.14; $p=0.014$ ) compared with SRS (OR 1.54; 95\% CI 0.87-2.73; $\mathrm{p}=0.14$ ) or the observation cohort (reference group). However, after multivariable adjustment, these differences were no longer found to be statistically significant [observation (reference), SRS (OR $1.64 ; 95 \%$ CI $0.86-3.14 ; \mathrm{p}=0.13$ ), microsurgery (OR 1.63; $95 \%$ CI $0.78-3.40 ; \mathrm{p}=0.19)]$.

Among the 143 patients managed with microsurgery, $94(66 \%)$ underwent retrosigmoid craniotomy, 34 (24\%) translabyrinthine resection, and $15(10 \%)$ the middle fossa approach. Overall, 45 (31\%) of the patients who underwent microsurgery had severe headache disability (HDI > 14) at time of survey, with the percentage of patients within each subgroup being very similar: 5 of $15(33 \%)$ middle fossa craniotomy, 29 of 94 (31\%) retrosigmoid craniotomy, and 11 of $34(32 \%)$ translabyrinthine resection. Univariately, the risk of long-term severe headache disability was not different between patients who underwent retrosigmoid craniotomy (reference group), translabyrinthine resection (OR 1.07; 95\% CI 0.46-2.49; $\mathrm{p}=0.87$ ), and middle fossa craniotomy (OR 1.12; 95\% CI 0.35-3.57; $\mathrm{p}=0.85$ ). The relatively small number of patients with severe HDI scores within the individual subgroups precluded multivariable analysis.

Within the SRS group, there were 179 patients (72\%) who received a marginal dose of $12 \mathrm{~Gy}, 42(17 \%)$ who received $13 \mathrm{~Gy}$, and $26(11 \%)$ who received $14 \mathrm{~Gy}$. Univariately, the OR for the marginal dose 13 Gy versus 12 Gy to predict severe headache disability (HDI > 14) was 0.70 (95\% CI $0.30-1.63 ; p=0.41)$; the OR for the marginal dose 14 Gy versus 12 Gy was 0.39 (95\% CI $0.11-1.36$; $p=$ $0.14)$. There were only 56 patients within the SRS cohort who had severe headache disability at time of survey, as shown in Table 3. As such, multivariable modeling could not be performed in this subset.

\section{Predictors of Long-Term Headache Disability}

Among the 538 patients with VS, the mean HDI total score was 10 (median 2; IQR 0-14; range 0-95), and there were 275 patients $(51 \%)$ with HDI total scores $>0$. Univariate associations of the candidate predictors for an HDI total score of $>0$ are summarized in Table 4. Younger age, female sex, preexisting diagnosis of migraine, presence of headaches prior to treatment, treatment with microsurgery, and higher (poorer) HADS total score at time 
TABLE 2. Comparison of features between patients with conservatively observed VS and nontumor controls

\begin{tabular}{|c|c|c|c|}
\hline \multirow[b]{2}{*}{ Feature } & \multicolumn{2}{|c|}{ Mean (median; IQR) or No. (\%) } & \multirow[b]{2}{*}{$\mathrm{p}$ Value } \\
\hline & Controls $n=103$ & Observation $n=148$ & \\
\hline Age at survey (yrs) & $55.1(56 ; 48-63)$ & $67.2(67 ; 61-74)$ & $<0.001$ \\
\hline \multicolumn{4}{|l|}{ Sex } \\
\hline Female & $61(59)$ & $88(59)$ & 0.97 \\
\hline Male & $42(41)$ & $60(41)$ & \\
\hline \multicolumn{4}{|l|}{ Preexisting Dx of migraine } \\
\hline No & $92(89)$ & $112(76)$ & 0.006 \\
\hline Yes & $11(11)$ & $36(24)$ & \\
\hline \multicolumn{4}{|l|}{ Preexisting Dx of HAs $(n=250)$} \\
\hline No & $41(40)$ & $50(34)$ & 0.11 \\
\hline Yes, mild & $51(50)$ & $67(46)$ & \\
\hline Yes, severe & $11(11)$ & $30(20)$ & \\
\hline \multicolumn{4}{|c|}{ Change in HAs over last $5-10$ yrs $(n=247)$} \\
\hline Slightly better & $14(14)$ & $14(10)$ & 0.50 \\
\hline No change & $78(76)$ & $117(81)$ & \\
\hline Somewhat worse & $8(8)$ & $10(7)$ & \\
\hline Much worse & $2(2)$ & $4(3)$ & \\
\hline \multicolumn{4}{|c|}{ Frequency of HAs over last several mos ( $n=248$ ) } \\
\hline Less than once per mo & $70(69)$ & $94(64)$ & 0.47 \\
\hline Once per mo & $11(11)$ & $17(12)$ & \\
\hline Less than 4 per mo & $7(7)$ & $19(13)$ & \\
\hline Less than daily & $9(9)$ & $15(10)$ & \\
\hline Daily & $4(4)$ & $2(1)$ & \\
\hline \multicolumn{4}{|c|}{ Severity of ongoing HAs $(n=242)$} \\
\hline Mild & $77(79)$ & $97(67)$ & 0.048 \\
\hline Moderate & $19(19)$ & $39(27)$ & \\
\hline Severe & $2(2)$ & $8(6)$ & \\
\hline HADS total score & $7.1(6 ; 3-10)$ & $5.9(4 ; 2-8)$ & 0.063 \\
\hline HDI total score $>0$ & $30(29)$ & $67(45)$ & 0.010 \\
\hline HDI total score $>14$ & $11(11)$ & $30(20)$ & 0.043 \\
\hline
\end{tabular}

of survey were univariately associated with an HDI score $>0$. The multivariable model developed for this end point is summarized in Table 5. After adjusting for baseline differences between treatment groups, the proportion of patients with an HDI score $>0$ was not statistically significantly different between treatment modalities. Overall, the presence of headache prior to treatment was the strongest predictor of long-term headache disability.

There were 131 patients $(24 \%)$ with HDI total scores $>14$, indicating severe headache disability. Univariate associations of the candidate predictors for HDI total scores $>14$ were similar to those seen for HDI $>0$ and are summarized in Table 6. The multivariable model developed for this end point demonstrates that younger age, higher (poorer) HADS total score, preexisting diagnosis of migraine, and presence of headaches prior to treatment are associated with severe long-term headache disability (Table 7).

Within the multivariable model, there was no significant association between HDI outcome and treatment center. Specifically, the OR for the Norwegian cohort versus the US population in the multivariable model for the primary outcome of having any headache disability (HDI $>0$ ) was 1.50 (95\% CI 0.99-2.27; p = 0.058), while the OR in the multivariable model for the primary outcome of severe headache disability (HDI > 14) was $1.22(95 \%$ CI $0.73-2.02 ; \mathrm{p}=0.45$ ).

\section{Discussion}

The current literature evaluating headache in patients with VS remains limited. To date, most studies have focused on pain following microsurgical resection and, in particular, retrosigmoid craniotomy. $1,8,9,14,15,17,21,24,28,33,36-38$ This narrow focus has potentially left several significant knowledge gaps. The current study examined headache outcomes among 538 patients with sporadic $<3-\mathrm{cm}$ VS who were managed with microsurgery, SRS, and observation, using a validated headache disability inventory. Additionally, 103 nontumor control patients were surveyed. The primary objectives were 1) to examine the influence of disease and treatment on headache in patients with sporadic VS; and 2) to identify clinical predictors of long-term headache disability.

\section{Prevalence of Headache in Patients With Sporadic VS}

Overall, $60 \%$ of patients reported having varying severities of headache prior to treatment, and $19 \%$ recorded a positive history of migraine. Surprisingly, the net change in perceived headache symptoms at a mean of 7.7 years 
TABLE 3. Univariate comparison of features among 538 patients treated with SRS, observation, or microsurgery

\begin{tabular}{|c|c|c|c|c|c|c|c|}
\hline \multirow[b]{2}{*}{ Feature } & \multicolumn{3}{|c|}{$\begin{array}{c}\text { Tx Modality } \\
\text { Mean (median; IQR) or No. (\%) }\end{array}$} & \multirow[b]{2}{*}{$\begin{array}{c}\text { Global } \\
\text { Comparison }\end{array}$} & \multicolumn{3}{|c|}{ Pairwise Comparison } \\
\hline & $\begin{array}{l}\text { SRS } \\
n=247\end{array}$ & $\begin{array}{l}\text { Observation } \\
n=148\end{array}$ & $\begin{array}{l}\text { Microsurgery } \\
n=143\end{array}$ & & SRS vs Ob & $\begin{array}{c}\text { SRS vs } \\
\text { Microsurgery }\end{array}$ & $\begin{array}{l}\text { Microsurgery } \\
\text { vs Ob }\end{array}$ \\
\hline HDI total score $>0$ (any HA disability) & $122(49)$ & $67(45)$ & $86(60)$ & 0.031 & 0.43 & 0.040 & 0.011 \\
\hline $\begin{array}{l}\text { HDI total score >14 (severe HA dis- } \\
\text { ability) }\end{array}$ & $56(23)$ & $30(20)$ & $45(31)$ & 0.059 & & & \\
\hline HADS total score $(n=537)$ & $6.1(4 ; 2-9)$ & $5.9(4 ; 2-8)$ & $6.9(5 ; 2-9)$ & 0.57 & & & \\
\hline $\begin{array}{l}\text { Tumor size }(n=533) \\
\quad \text { Intracanalicular } \\
0-9 \mathrm{~mm} \text { CPA } \\
10-19 \mathrm{~mm} \text { CPA } \\
20-30 \mathrm{~mm} \mathrm{CPA}\end{array}$ & $\begin{array}{r}35(14) \\
65(26) \\
128(52) \\
19(8)\end{array}$ & $\begin{array}{c}86(60) \\
30(21) \\
26(18) \\
1(1)\end{array}$ & $\begin{array}{l}33(23) \\
17(12) \\
57(40) \\
36(25)\end{array}$ & $<0.001$ & $<0.001$ & 0.051 & $<0.001$ \\
\hline $\begin{array}{l}\text { Hydrocephalus prior to Tx }(n=459) \\
\text { No } \\
\text { Yes }\end{array}$ & $\begin{array}{c}224(98) \\
5(2)\end{array}$ & $\begin{array}{l}88(100) \\
0\end{array}$ & $\begin{array}{c}139(98) \\
3(2)\end{array}$ & 0.51 & & & \\
\hline $\begin{array}{l}\text { Preexisting Dx of migraine } \\
\text { No } \\
\text { Yes }\end{array}$ & $\begin{array}{r}210(85) \\
37(15)\end{array}$ & $\begin{array}{r}112(76) \\
36(24)\end{array}$ & $\begin{array}{r}113(79) \\
30(21)\end{array}$ & 0.060 & & & \\
\hline $\begin{array}{l}\text { Presence of HAs prior to Tx }(n=537) \\
\text { No } \\
\text { Yes, mild } \\
\text { Yes, severe }\end{array}$ & $\begin{array}{r}109(44) \\
86(35) \\
52(21)\end{array}$ & $\begin{array}{l}50(34) \\
67(46) \\
30(20)\end{array}$ & $\begin{array}{l}60(42) \\
60(42) \\
23(16)\end{array}$ & 0.28 & & & \\
\hline $\begin{array}{l}\text { Change in HAs following Tx }(n=530) \\
\text { Slightly better } \\
\text { No change } \\
\text { Somewhat worse } \\
\text { Much worse }\end{array}$ & $\begin{array}{c}35(14) \\
174(72) \\
25(10) \\
9(4)\end{array}$ & $\begin{array}{c}14(10) \\
117(81) \\
10(7) \\
4(3)\end{array}$ & $\begin{array}{l}27(19) \\
80(56) \\
20(14) \\
15(11)\end{array}$ & 0.47 & & & \\
\hline $\begin{array}{l}\text { Frequency of HAs over last several } \\
\text { mos ( } n=535) \\
\text { Less than once per mo } \\
\text { Once per mo } \\
\text { Less than } 4 \text { per mo } \\
\text { Less than daily } \\
\text { Daily }\end{array}$ & $\begin{array}{c}149(61) \\
25(10) \\
33(13) \\
29(12) \\
9(4)\end{array}$ & $\begin{array}{l}94(64) \\
17(12) \\
19(13) \\
15(10) \\
2(1)\end{array}$ & $\begin{array}{l}65(45) \\
11(8) \\
39(27) \\
22(15) \\
6(4)\end{array}$ & 0.001 & 0.38 & 0.003 & $<0.001$ \\
\hline $\begin{array}{l}\text { Severity of ongoing HAs }(n=522) \\
\text { Mild } \\
\text { Moderate } \\
\text { Severe }\end{array}$ & $\begin{array}{r}157(66) \\
65(27) \\
15(6)\end{array}$ & $\begin{array}{l}97(67) \\
39927) \\
8(6)\end{array}$ & $\begin{array}{l}80(57) \\
48(34) \\
13(9)\end{array}$ & 0.094 & & & \\
\hline
\end{tabular}

$\mathrm{Ob}=$ observation; $\mathrm{SRS}$ = stereotactic radiosurgery.

following treatment appeared nearly stable, with $14 \%$ noting improvement, $16 \%$ with worsening headache, and $70 \%$ having no perceivable change. At time of survey, $42 \%$ of the 538 patients reported having at least one headache per month within the preceding several months, with more than one-third of patients experiencing moderate to severe pain.

Although there are currently no studies in the VS literature focusing on longitudinal change in headache symptoms following SRS and conservative observation, surgical series have reported a frequency of baseline headache ranging from $9 \%$ to $50 \%$ and a prevalence of posttreatment headache ranging from $0 \%$ to $75 \% .{ }^{17,24,28,37,38,44,45,47}$ The low rate of headache seen in some studies is perplexing since, within the general population, the estimated lifetime prevalence of headache is approximately $60 \%-80 \%$, with roughly $40 \%-60 \%$ of individuals experiencing headaches each year. ${ }^{42,43}$ This significant disparity probably stems from heterogeneous study methodology, varying definitions of headache, and differing lengths of follow-up. Several studies have used subjective cut-offs that only included patients with "problematic" or "bothersome" headaches. It has also been well established that the frequency of postoperative headache significantly declines with duration of follow-up-postoperative headaches are generally more severe immediately after surgery and improve significantly even by the 1 st year. ${ }^{14,36}$ Finally, studies using prospective or cross-sectional questionnaires generally report a higher prevalence of headache and more closely approximate estimates from general population epidemiological studies, whereas retrospective chart reviews more frequently report significantly lower rates. This probably 
TABLE 4. Univariate associations with any headache disability (HDI total scores $>0$ ) in 538 patients with VS

\begin{tabular}{|c|c|c|c|c|}
\hline \multirow[b]{2}{*}{ Feature } & \multicolumn{2}{|c|}{ Median or No. (\%) } & \multirow[b]{2}{*}{ OR $(95 \% \mathrm{Cl})$} & \multirow[b]{2}{*}{$p$ Value } \\
\hline & HDI Score $>0$ n = 275 & HDI Score $=0 n=263$ & & \\
\hline \multicolumn{5}{|l|}{ Baseline features } \\
\hline Age at survey (yrs) & 61 & 68 & $0.64(0.55-0.75)^{\star}$ & $<0.001$ \\
\hline Dx to survey (yrs) & 7.4 & 7.7 & $1.00(0.93-1.07) \dagger$ & 0.96 \\
\hline \multicolumn{5}{|l|}{ Sex } \\
\hline Female & $178(65)$ & $125(48)$ & 1.0 (reference) & \\
\hline Male & $97(35)$ & $138(52)$ & $0.49(0.35-0.70)$ & $<0.001$ \\
\hline \multicolumn{5}{|l|}{ Pre-Tx } \\
\hline \multicolumn{5}{|l|}{ Tumor size } \\
\hline Intracanalicular & $73(27)$ & $81(31)$ & 1.0 (reference) & \\
\hline 0-9 mm CPA & 49 (18) & $63(24)$ & $0.86(0.53-1.41)$ & 0.56 \\
\hline $10-19 \mathrm{~mm}$ CPA & $123(45)$ & $88(34)$ & $1.55(1.02-2.36)$ & 0.040 \\
\hline 20-30 mm CPA & $29(11)$ & $27(10)$ & $1.19(0.65-2.20)$ & 0.57 \\
\hline \multicolumn{5}{|l|}{ Hydrocephalus } \\
\hline No & $239(99)$ & $212(98)$ & 1.0 (reference) & \\
\hline Yes & $3(1)$ & $5(2)$ & $0.53(0.13-2.25)$ & 0.39 \\
\hline \multicolumn{5}{|c|}{ Preexisting Dx of migraine } \\
\hline No & $194(71)$ & $241(92)$ & 1.0 (reference) & \\
\hline Yes & $81(29)$ & $22(8)$ & $4.57(2.75-7.60)$ & $<0.001$ \\
\hline \multicolumn{5}{|c|}{ Presence of HAs prior to Tx } \\
\hline No & $59(21)$ & $160(61)$ & 1.0 (reference) & \\
\hline Yes, mild & $127(46)$ & $86(33)$ & $4.01(2.67-6.00)$ & $<0.001$ \\
\hline Yes, severe & $89(32)$ & $16(6)$ & 15.08 (8.19-27.76) & $<0.001$ \\
\hline \multicolumn{5}{|l|}{ Tx modality } \\
\hline Observation & $67(24)$ & $81(31)$ & 1.0 (reference) & \\
\hline SRS & $122(44)$ & $125(48)$ & $1.18(0.78-1.78)$ & 0.43 \\
\hline Microsurgery & $86(31)$ & $57(22)$ & $1.82(1.15-2.91)$ & 0.011 \\
\hline \multicolumn{5}{|l|}{ Post-Tx } \\
\hline HADS total score & 6 & 3 & $1.12(1.08-1.16) \dagger$ & $<0.001$ \\
\hline
\end{tabular}

relates to an inherent limitation of a retrospective study; if a symptom is not mentioned in the clinical note, it may be recorded as negative rather than removing the missing feature from the denominator, potentially leading to a significant underestimation of prevalence.

\section{Do Small Sporadic VSs Cause Headache?}

It is commonly held that VSs do not result in headache symptoms until they are large enough to impinge upon the fifth cranial nerve or cause obstructive hydrocephalus from fourth ventricle effacement. Though there are currently very limited data in the VS literature to validate or discredit this notion, there is convincing evidence within the general neurosurgical literature that intracranial neoplasms contribute to headache, with posterior fossa lesions being more likely than supratentorial tumors to cause head pain. ${ }^{30,44,45}$ Mechanisms of headache from intracranial tumors include elevated intracranial pressure from hydrocephalus or venous outflow obstruction, secondary parenchymal or subarachnoid bleed, or traction and compression of pain-sensitive dura mater, meningeal vasculature, or cranial nerves carrying sensory contributions such as the trigeminal, facial, glossopharyngeal, vagus, or upper cer- vical rootlets. ${ }^{6,44}$ Suwanwela and colleagues examined the pattern of headache associated with various intracranial tumors. They identified that 15 of 17 (88\%) patients with VS reported headache, which is similar to glioma (26 of $29 ; 90 \%)$ and more frequent than with metastatic tumors $(16$ of $24 ; 67 \%){ }^{44}$

To investigate this issue further, we compared headache symptoms and HDI scores between 148 patients with conservatively observed tumors and 103 general population nontumor control subjects. Sixty percent of observed VSs were purely intracanalicular and only 1 patient had a tumor larger than $2 \mathrm{~cm}$; none had hydrocephalus. While the observation group had a higher prevalence of migraine, there was no difference in the rate of preexisting headaches, change in headache symptoms over the last 5-10 years, and frequency of headaches over the last several months. However, the perceived severity of ongoing headaches and HDI scores at time of survey were statistically significantly greater in the observation group. Overall, the risk of having severe headache disability (HDI $>14$ points) with a small or medium-sized untreated VS was roughly twice that of the general population. Emotional distress from diagnosis cannot account for this difference since the nontumor 
TABLE 5. Multivariable model to predict any headache disability (HDI total scores $>0$ ) in 521 patients with VS

\begin{tabular}{lcc}
\hline \multicolumn{1}{c}{ Feature } & OR $(95 \% \mathrm{Cl})$ & $\mathrm{p}$ Value \\
\hline Age at survey (yrs) & $0.67(0.57-0.80)^{*}$ & $<0.001$ \\
\hline HADS total score & $1.09(1.04-1.14) \dagger$ & $<0.001$ \\
\hline Sex & & \\
$\quad$ Female & 1.0 (reference) & \\
$\quad$ Male & $0.59(0.39-0.88)$ & 0.011 \\
\hline Presence of HAs prior to treatment & & \\
$\quad$ No & 1.0 (reference) & \\
Yes, mild & $3.22(2.09-4.96)$ & $<0.001$ \\
$\quad$ Yes, severe & $11.12(5.84-21.17)$ & $<0.001$ \\
\hline * OR and Cl represent a 10-unit increase. & & \\
$\dagger$ OR and Cl represent a 1-unit increase. & &
\end{tabular}

control group actually had slightly poorer HADS results. We speculate that the most plausible explanation for increased headache disability with small VS is from dural traction within the internal auditory canal and at the porus acusticus. This is further supported by the observation that headache most commonly lateralizes to the side with the tumor. ${ }^{24,44}$ Seventh nerve compression is also conceivable; however, it is very rare that patients report otalgia, such as with geniculate neuralgia or herpes zoster oticus, making this much less likely. ${ }^{10,24}$ Last, it is possible that tumor population selection bias also at least partially contributed to this difference. That is, in the absence of other symptoms, patients who are harboring undiagnosed VS with headache are more likely to undergo head MRI than those without headache.

\section{Impact of Treatment on Headache}

To date, there are very limited data comparing headache outcomes between treatment modalities, and no single study has specifically focused on this issue. In the current study, after accounting for baseline differences between treatment groups, HDI outcomes were not statistically significantly different among treatment modalities.

In a previous study, we found that long-term headache, determined by the PANQOL pain domain, was greater for patients receiving microsurgery compared with SRS or observation. ${ }^{5}$ Using the same measure, Robinett et al. reported a similar finding at $0-5$ years of follow up; however, no statistically significant difference in pain was iden-

TABLE 6. Univariate associations with severe headache disability (HDI total scores > 14) in 538 patients with VS

\begin{tabular}{|c|c|c|c|c|}
\hline \multirow[b]{2}{*}{ Feature } & \multicolumn{2}{|c|}{ Median or No. (\%) } & \multirow[b]{2}{*}{ OR $(95 \% \mathrm{Cl})$} & \multirow[b]{2}{*}{ p Value } \\
\hline & HDI Score > 14 n = 131 & HDI Score $\leq 14 n=407$ & & \\
\hline \multicolumn{5}{|l|}{ Baseline features } \\
\hline Age at survey (yrs) & 59 & 66 & $0.65(0.55-0.77)^{*}$ & $<0.001$ \\
\hline Dx to survey (yrs) & 7.7 & 7.6 & $1.02(0.94-1.10) \dagger$ & 0.71 \\
\hline \multicolumn{5}{|l|}{ Sex } \\
\hline Female & $89(68)$ & $214(53)$ & 1.0 (reference) & \\
\hline Male & $42(32)$ & $193(47)$ & $0.52(0.35-0.79)$ & 0.002 \\
\hline \multicolumn{5}{|l|}{ Pre-Tx } \\
\hline \multicolumn{5}{|l|}{ Tumor size } \\
\hline Intracanalicular & $38(29)$ & $116(29)$ & 1.0 (reference) & \\
\hline 0-9 mm CPA & $19(15)$ & $93(23)$ & $0.62(0.34-1.15)$ & 0.13 \\
\hline $10-19 \mathrm{~mm}$ CPA & $56(43)$ & $155(38)$ & $1.10(0.68-1.78)$ & 0.69 \\
\hline 20-30 mm CPA & $17(13)$ & $39(10)$ & $1.33(0.68-2.62)$ & 0.41 \\
\hline \multicolumn{5}{|l|}{ Hydrocephalus } \\
\hline No & $113(97)$ & $338(99)$ & 1.0 (reference) & \\
\hline Yes & $3(3)$ & $5(1)$ & $1.80(0.42-7.63)$ & 0.43 \\
\hline \multicolumn{5}{|c|}{ Preexisting Dx of migraine } \\
\hline No & $79(60)$ & $356(87)$ & 1.0 (reference) & \\
\hline Yes & $52(40)$ & $51(13)$ & $4.60(2.91-7.26)$ & $<0.001$ \\
\hline \multicolumn{5}{|c|}{ Presence of HAs prior to Tx } \\
\hline No & $22(17)$ & $197(49)$ & 1.0 (reference) & \\
\hline Yes, mild & $46(35)$ & $167(41)$ & $2.47(1.43-4.27)$ & 0.001 \\
\hline Yes, severe & $63(48)$ & $42(10)$ & $13.43(7.45-24.19)$ & $<0.001$ \\
\hline \multicolumn{5}{|l|}{ Tx modality } \\
\hline Observation & $30(23)$ & $118(29)$ & 1.0 (reference) & \\
\hline SRS & $56(43)$ & $191(47)$ & $1.15(0.70-1.90)$ & 0.58 \\
\hline Microsurgery & $45(34)$ & $98(24)$ & $1.81(1.06-3.08)$ & 0.030 \\
\hline \multicolumn{5}{|l|}{ Post-Tx } \\
\hline HADS total score & 8 & 4 & $1.14(1.10-1.19) \dagger$ & $<0.001$ \\
\hline
\end{tabular}


tified between groups after 5 years. ${ }^{34}$ Other studies have similarly demonstrated that differences in pain are greatest early after treatment; however, this disparity significantly declines within several years. ${ }^{29}$

A number of studies evaluating pain after microsurgery have demonstrated that retrosigmoid craniotomy has a higher early prevalence of headache compared with translabyrinthine and middle fossa resection. . $^{1928,36,37,45}$ There are many explanations for this finding. Several studies have demonstrated a reduction in postoperative headache after using cranioplasty, suggesting that adhesions between nuchal muscles and posterior fossa dura may cause pain. ${ }^{15,21,33}$ Jackson et al. compared the rate of postoperative headache following retrosigmoid craniotomy for vestibular nerve section and VS surgery and found that headache following tumor resection was substantially greater, suggesting that headache resulted from disseminated intracranial bone dust from drilling the porus of the internal auditory canal at the time of resection, causing aseptic meningitis..$^{13,17}$ Ducic et al. reported significant improvement in headache following occipital nerve resection in 6 of 7 patients, implicating nerve entrapment or neuroma formation. ${ }^{9}$ Levo reported a marked improvement or resolution of pain in 9 subjects using sumatriptan, leading to the conclusion that some postoperative headache may be mediated by the trigeminal nerve. ${ }^{23}$

In the current study, both participating centers used very similar techniques for the retrosigmoid approach. A vertically oriented retroauricular curvilinear incision was made, and a craniotomy was performed following a single bur hole placed just below the transverse-sigmoid sinus junction, preserving a bone flap. Following tumor resection, bone dust was meticulously evacuated from the cistern, the dura was closed primarily, and Gelfoam was placed over the dura. The bone flap was replaced by securing it with standard titanium microplates and screws. Polymethylmethacrylate or other methods of cranioplasty were not performed.

Several studies have demonstrated that the severity of headache following retrosigmoid craniotomy decreases with time..$^{14,17,36-38}$ Ruckenstein et al. examined 52 patients who underwent translabyrinthine and retrosigmoid craniotomy for VS and reported a higher prevalence of headache at 1 and 6 months with retrosigmoid surgery; however, at 1 year, there was no difference between groups. ${ }^{36}$ The comparison between middle cranial fossa and other approaches is not as well studied. A systematic review found that retrosigmoid craniotomy had the highest prevalence of headache, translabyrinthine resection had the lowest, and middle cranial fossa had an intermediate rank. ${ }^{1}$ Although translabyrinthine resection and middle fossa craniotomy limit intracranial bone dust from extradural drilling, division of the temporalis muscle with middle cranial fossa may explain the higher rate of pain. This theory is corroborated by the high frequency of myofascial pain involving the temporalis muscle experienced by patients undergoing open cerebral aneurysm repair. ${ }^{35}$

\section{Clinical Predictors of Long-Term Headache Disability}

In the current study, we identified several predictors of long-term headache disability. In a multivariable model, younger age, higher (poorer) HADS total score, female
TABLE 7. Multivariable model to predict severe headache disability (HDI total scores > 14) in 538 patients with VS

\begin{tabular}{llr}
\hline \multicolumn{1}{c}{ Feature } & \multicolumn{1}{c}{ OR $(95 \% \mathrm{Cl})$} & p Value \\
\hline Age at survey (yrs) & $0.69(0.57-0.84)^{*}$ & $<0.001$ \\
\hline HADS total score & $1.15(1.10-1.20) \dagger$ & $<0.001$ \\
\hline Preexisting Dx of migraine & & \\
$\quad$ No & 1.0 (reference) & \\
$\quad$ Yes & $1.82(1.01-3.29)$ & 0.046 \\
\hline Presence of HAs prior to Tx & & \\
$\quad$ No & $1.0($ reference) & \\
$\quad$ Yes, mild & $1.80(0.99-3.30)$ & 0.056 \\
$\quad$ Yes, severe & $8.84(4.36-17.93)$ & $<0.001$ \\
\hline * OR and Cl represent a 10-unit increase. & \\
$\dagger$ OR and Cl represent a 1-unit increase.
\end{tabular}

sex, and preexisting diagnosis of headaches were associated with HDI scores $>0$. When specifically analyzing predictors of severe headache disability (HDI $>14$ ), younger age, HADS total score, preexisting diagnosis of migraine, and presence of headaches prior to treatment were statistically significant. When considering all factors, a preexisting diagnosis of headache was the strongest predictor of poor HDI total score. Ryzenman et al. analyzed postoperative headache results from the 1998 Acoustic Neuroma Association survey including 1657 surgically treated patients who were surveyed a mean of 8 years after treatment. ${ }^{37}$ Similar to the current study, pretreatment headache, female sex, and younger age were identified to be associated with poorer postoperative headache outcomes. Levo and colleagues evaluated 251 patients who underwent resection of VS and found that after a mean of 8.9 years, persistent headache was associated with the retrosigmoid approach, small tumor size, gait problems, and preoperative headache. $^{24}$

It is notable that younger age and female sex are also strongly associated with headache within the general population. ${ }^{42,43}$ Additionally, it has been shown that anxiety and depression heavily influence headache symptoms. ${ }^{20,25,33,46}$ Therefore, the factors that most significantly influence long-term headache in VS are not specific to the diagnosis, but rather are the same predictors for headache in the general population. The importance of asking about baseline headaches cannot be overemphasized. Unfortunately, in the clinical setting, headaches after treatment are frequently blamed on the treatment itself, even in the presence of a preexisting headache syndrome. The fact that the longterm prevalence of headache in patients with VS closely matches that in the general population, and that the number one predictor of posttreatment headache is the existence of pretreatment headache, suggest that long-term headache may actually have more to do with the patient than with the diagnosis of VS or its treatment. Based on this current analysis, we no longer specifically counsel patients with a headache history that they should strongly avoid microsurgery as a treatment option for their VS.

\section{Headache Classification and Treatment}

Whereas the current study did not attempt to classify headache subtypes or determine response to therapy, several previous studies have examined symptom profiles to 
categorize headache types according to the International Classification of Headache Disorders, Second Edition (ICHD-II) diagnostic criteria..$^{13,33,39}$ Rimaaja and colleagues characterized pre- and postoperative headache in 61 and 122 patients, respectively. ${ }^{33}$ Before surgery, 77\% of patients had migraine with or without aura, $15 \%$ had tension-type headache, and the remaining patients were unclassified. Following surgery, 89 of the 122 patients with headache experienced postoperative headache only, whereas 39 reported both pre- and postoperative headache. New postoperative headache met ICHD-II diagnostic criteria for tension-type headache in 4 cases, and for migraine with or without aura in 15 , with most remaining patients fitting a specific subgroup of postcraniotomy headache. Schankin et al. found that among 30 patients with severe ( $\geq 6$ of 10 pain) postoperative headache persisting beyond 6 months, $47 \%$ had tension-type headache, $17 \%$ occipital neuralgia, $17 \%$ trigeminal neuralgia, $10 \%$ nervus intermedius neuralgia, and $10 \%$ cervicogenic headache. ${ }^{39}$

Levo et al. reported that approximately one-quarter of patients with postoperative headache did not require pain medications, more than three-quarters had symptomatic improvement or resolution of pain with antiinflammatory agents, and only $3 \%$ received no help from medication. ${ }^{24}$ Similarly, Rimaaja and colleagues found that simple analgesics (nonsteroidal antiinflammatories, coxibs, or acetaminophen) provided partial or complete pain relief in $79 \%$ of patients with postoperative headache, whereas antiepileptic agents (gabapentin and carbamazepine), tricyclic antidepressants, and muscle relaxants were used much less frequently. ${ }^{33}$ Finally, Hanson et al. reported their experience managing pain after suboccipital VS resection, finding that approximately $13 \%$ of patients did not respond to simple analgesic therapy. ${ }^{13}$ Within the small group of patients with refractory symptoms, divalproex sodium and verapamil provided significant relief in all cases.

We wish to acknowledge several strengths and limitations of the current study. To date, the majority of publications investigating headache in VS have examined relatively early postoperative symptoms in a limited sample size using self-devised questionnaires. To our knowledge, no study has characterized headache in conservatively managed patients or in those receiving SRS. Furthermore, none have used a validated headache disability questionnaire to assess the impact of headache on daily life. In the current study, we compared long-term headache outcomes among patients managed with observation, SRS, and microsurgery. Additionally, a nontumor control group was surveyed to determine the impact of diagnosis on headache.

The primary limitation of the current study is the lack of baseline or longitudinal data to evaluate change in headache disability and symptomatology over time. Patients were required to recollect symptoms that were present many years earlier, introducing the risk of recall bias. Additionally, these data provide a cross-sectional snapshot of headache disability at approximately 8 years following treatment and do not describe disability in the early period after treatment, which may be different, particularly for the surgical cohort. Furthermore, despite using a validated inventory, questionnaire responses assessing handicap are subjective -2 patients with similar headache severity and frequency may give significantly different responses. Finally, headache subtype and response to therapy were not characterized, given the retrospective nature of the study.

\section{Conclusions}

At a mean of approximately 8 years following treatment, $42 \%$ of VS patients were experiencing at least monthly headaches. When analyzing all patients, we found no difference in long-term HDI scores among treatment groups. Multivariable regression revealed that patientrelated features such as age, sex, pretreatment headache, and emotional distress are the strongest predictors of longterm headache disability, whereas disease-associated features including tumor size and treatment modality have much less influence.

\section{Acknowledgment}

We thank Christine M. Lohse, MS, from the Department of Health Sciences Research for her valuable assistance with statistical analysis and manuscript review.

\section{References}

1. Ansari SF, Terry C, Cohen-Gadol AA: Surgery for vestibular schwannomas: a systematic review of complications by approach. Neurosurg Focus 33(3):E14, 2012

2. Betchen SA, Walsh J, Post KD: Self-assessed quality of life after acoustic neuroma surgery. J Neurosurg 99:818-823, 2003

3. Breivik CN, Varughese JK, Wentzel-Larsen T, Vassbotn F, Lund-Johansen M: Conservative management of vestibular schwannoma-a prospective cohort study: treatment, symptoms, and quality of life. Neurosurgery 70:1072-1080, 2012

4. Carlson M, Driscoll C, Neff B, Tombers N, Sullan M, Pollock B, et al: Quality-of-life comparing observation, microsurgery, and radiosurgery for small-to-medium sized vestibular schwannoma using a validated disease-specific instrument. Presented at the 23rd North American Skull Base Society Annual Meeting, Miami, 2013 (Abstract) (https://www. thieme-connect.com/products/ejournals/abstract/10.1055 /s-0033-1336258) [Accessed April 17, 2015]

5. Carlson M, Tveiten $\varnothing$, Driscoll C, Goplen F, Neff B, Pollock $\mathrm{B}$, et al: Long-term quality of life in patients with vestibular schwannoma: an international multicenter, cross-sectional study comparing microsurgery, stereotactic radiosurgery, observation, and non-tumor controls. J Neurosurg 122:833842,2015

6. Cohen JM: Teaching case: meningioma as the cause of daily headache? Headache 49:627-630, 2009

7. Committee on Hearing and Equilibrium: Guidelines for the evaluation of hearing preservation in acoustic neuroma (vestibular schwannoma). Otolaryngol Head Neck Surg 113:179-180, 1995

8. Driscoll CL, Beatty CW: Pain after acoustic neuroma surgery. Otolaryngol Clin North Am 30:893-903, 1997

9. Ducic I, Felder JM III, Endara M: Postoperative headache following acoustic neuroma resection: occipital nerve injuries are associated with a treatable occipital neuralgia. Headache 52:1136-1145, 2012

10. Eshraghi AA, Buchman CA, Telischi FF: Sensory auricular branch of the facial nerve. Otol Neurotol 23:393-396, 2002

11. Gauden A, Weir P, Hawthorne G, Kaye A: Systematic review of quality of life in the management of vestibular schwannoma. J Clin Neurosci 18:1573-1584, 2011

12. Gurgel RK, Dogru S, Amdur RL, Monfared A: Facial nerve outcomes after surgery for large vestibular schwannomas: do 
surgical approach and extent of resection matter? Neurosurg Focus 33(3):E16, 2012

13. Hanson MB, Glasscock ME III, Brandes JL, Jackson CG: Medical treatment of headache after suboccipital acoustic tumor removal. Laryngoscope 108:1111-1114, 1998

14. Harner SG, Beatty CW, Ebersold MJ: Headache after acoustic neuroma excision. Am J Otol 14:552-555, 1993

15. Harner SG, Beatty CW, Ebersold MJ: Impact of cranioplasty on headache after acoustic neuroma removal. Neurosurgery 36:1097-1100, 1995

16. Herrero MJ, Blanch J, Peri JM, De Pablo J, Pintor L, Bulbena A: A validation study of the hospital anxiety and depression scale (HADS) in a Spanish population. Gen Hosp Psychiatry 25:277-283, 2003

17. Jackson CG, McGrew BM, Forest JA, Hampf CR, Glasscock ME III, Brandes JL, et al: Comparison of postoperative headache after retrosigmoid approach: vestibular nerve section versus vestibular schwannoma resection. Am J Otol 21:412-416, 2000

18. Jacobson GP, Ramadan NM, Aggarwal SK, Newman CW: The Henry Ford Hospital Headache Disability Inventory (HDI). Neurology 44:837-842, 1994

19. Jørgensen BG, Pedersen CB: Acoustic neuroma. Follow-up of 78 patients. Clin Otolaryngol Allied Sci 19:478-484, 1994

20. Juang KD, Wang SJ, Fuh JL, Lu SR, Su TP: Comorbidity of depressive and anxiety disorders in chronic daily headache and its subtypes. Headache 40:818-823, 2000

21. Koperer H, Deinsberger W, Jödicke A, Böker DK: Postoperative headache after the lateral suboccipital approach: craniotomy versus craniectomy. Minim Invasive Neurosurg 42:175-178, 1999

22. Lassaletta L, Alfonso C, Del Rio L, Roda JM, Gavilan J: Impact of facial dysfunction on quality of life after vestibular schwannoma surgery. Ann Otol Rhinol Laryngol 115:694698,2006

23. Levo H, Blomstedt G, Hirvonen T, Pyykkö I: Causes of persistent postoperative headache after surgery for vestibular schwannoma. Clin Otolaryngol Allied Sci 26:401-406, 2001

24. Levo H, Pyykkö I, Blomstedt G: Postoperative headache after surgery for vestibular schwannoma. Ann Otol Rhinol Laryngol 109:853-858, 2000

25. Magalhães JE, Azevedo-Filho HR, Rocha-Filho PA: The risk of headache attributed to surgical treatment of intracranial aneurysms: a cohort study. Headache 53:1613-1623, 2013

26. Myrseth E, Møller P, Wentzel-Larsen T, Goplen F, LundJohansen M: Untreated vestibular schwannomas: vertigo is a powerful predictor for health-related quality of life. Neurosurgery 59:67-76, 2006

27. Patel J, Vasan R, van Loveren H, Downes K, Agazzi S: The changing face of acoustic neuroma management in the USA: analysis of the 1998 and 2008 patient surveys from the acoustic neuroma association. Br J Neurosurg 28:20-24, 2014

28. Pedrosa CA, Ahern DK, McKenna MJ, Ojemann RG, Acquadro MA: Determinants and impact of headache after acoustic neuroma surgery. Am J Otol 15:793-797, 1994

29. Pollock BE, Driscoll CL, Foote RL, Link MJ, Gorman DA, Bauch CD, et al: Patient outcomes after vestibular schwannoma management: a prospective comparison of microsurgical resection and stereotactic radiosurgery. Neurosurgery 59:77-85, 2006

30. Purdy RA, Kirby S: Headaches and brain tumors. Neurol Clin 22:39-53, 2004

31. Quintana JM, Padierna A, Esteban C, Arostegui I, Bilbao A, Ruiz I: Evaluation of the psychometric characteristics of the Spanish version of the Hospital Anxiety and Depression Scale. Acta Psychiatr Scand 107:216-221, 2003

32. Ramsden RT: The bloody angle: 100 years of acoustic neuroma surgery. J R Soc Med 88:464P-468P, 1995

33. Rimaaja T, Haanpää M, Blomstedt G, Färkkilä M: Headaches after acoustic neuroma surgery. Cephalalgia 27:1128-1135, 2007

34. Robinett ZN, Walz PC, Miles-Markley B, Moberly AC, Welling DB: Comparison of long-term quality-of-life outcomes in vestibular schwannoma patients. Otolaryngol Head Neck Surg 150:1024-1032, 2014

35. Rocha-Filho PA, Fujarra FJ, Gherpelli JL, Rabello GD, de Siqueira JT: The long-term effect of craniotomy on temporalis muscle function. Oral Surg Oral Med Oral Pathol Oral Radiol Endod 104:e17-e21, 2007

36. Ruckenstein MJ, Harris JP, Cueva RA, Prioleau G, Alksne $\mathrm{J}$ : Pain subsequent to resection of acoustic neuromas via suboccipital and translabyrinthine approaches. Am J Otol 17:620-624, 1996

37. Ryzenman JM, Pensak ML, Tew JM Jr: Headache: a quality of life analysis in a cohort of 1,657 patients undergoing acoustic neuroma surgery, results from the acoustic neuroma association. Laryngoscope 115:703-711, 2005

38. Schaller B, Baumann A: Headache after removal of vestibular schwannoma via the retrosigmoid approach: a long-term follow-up-study. Otolaryngol Head Neck Surg 128:387395,2003

39. Schankin CJ, Gall C, Straube A: Headache syndromes after acoustic neuroma surgery and their implications for quality of life. Cephalalgia 29:760-771, 2009

40. Spinhoven P, Ormel J, Sloekers PP, Kempen GI, Speckens AE, Van Hemert AM: A validation study of the Hospital Anxiety and Depression Scale (HADS) in different groups of Dutch subjects. Psychol Med 27:363-370, 1997

41. Stangerup SE, Caye-Thomasen P, Tos M, Thomsen J: The natural history of vestibular schwannoma. Otol Neurotol 27:547-552, 2006

42. Stovner LJ, Hagen K, Jensen R, Katsarava Z, Lipton R, Scher A, et al: The global burden of headache: a documentation of headache prevalence and disability worldwide. Cephalalgia 27:193-210, 2007

43. Stovner LJ, Andree C: Prevalence of headache in Europe: a review for the Eurolight project. J Headache Pain 11:289299, 2010

44. Suwanwela N, Phanthumchinda K, Kaoropthum S: Headache in brain tumor: a cross-sectional study. Headache 34:435438, 1994

45. Taylor LP: Mechanism of brain tumor headache. Headache 54:772-775, 2014

46. Torelli P, Lambru G, Manzoni GC: Psychiatric comorbidity and headache: clinical and therapeutical aspects. Neurol Sci 27 (Suppl 2):S73-S76, 2006

47. Vijayan N: Postoperative headache in acoustic neuroma. Headache 35:98-100, 1995

48. Zigmond AS, Snaith RP: The hospital anxiety and depression scale. Acta Psychiatr Scand 67:361-370, 1983

\section{Author Contributions}

Conception and design: Carlson, Tveiten, Goplen, LundJohansen, Link. Acquisition of data: Carlson, Tveiten, Sullan, Goplen, Lund-Johansen, Link. Analysis and interpretation of data: all authors. Drafting the article: Carlson, Boes, Link. Critically revising the article: Carlson, Tveiten, Driscoll, Boes, Lund-Johansen, Link. Reviewed submitted version of manuscript: all authors. Approved the final version of the manuscript on behalf of all authors: Carlson. Statistical analysis: Carlson, Tveiten.

\section{Correspondence}

Matthew L. Carlson, Department of Otolaryngology-Head and Neck Surgery, Mayo Clinic, 200 First St. SW, Rochester, MN 55905. email: carlson.matthew@mayo.edu. 